\title{
Expression of atresia biomarkers in granulosa cells after ovarian stimulation in heifers
}

\author{
David A Landry, Lia Rossi-Perazza, Simon Lafontaine and Marc-André Sirard \\ Centre de Recherche en Reproduction, Développement et Santé Intergénérationnelle (CRDSI), Département des \\ Sciences Animales, Faculté des Sciences de l'Agriculture et de l'Alimentation, Université Laval, Québec, Canada
}

Correspondence should be addressed to M-A Sirard; Email: marc-andre.sirard@fsaa.ulaval.ca

\begin{abstract}
The use of younger gamete donors in dairy cattle genetic selection programs significantly accelerates genetic gains by decreasing the interval between generations. Ovarian stimulation (OS) and the practice of follicle-stimulating hormone (FSH) withdrawal, also known as coasting, are intensively used in pre-pubertal heifers without detrimental effects on subsequent reproductive performance but generally with lower embryo yields. However, recent data from embryo transfer programs showed similar embryo yields in younger and sexually mature animals but with a significant difference in the coasting period. The aim of the present study was to identify a set of granulosa cell biomarkers capable of distinguishing optimal follicle differentiation from late differentiation and atresia in order to assess the differences in coasting dynamics between pre- and post-pubertal donors. We integrated transcriptomic data sets from a public depository and used vote counting meta-analysis in order to elucidate the molecular changes occurring in granulosa cells during late follicle differentiation and atresia. The meta-analysis revealed the gene expression associated with follicle demise, and most importantly, identified potential biomarkers of that status in bovine granulosa cells. The comparison of the expression of six biomarkers between pre- and post-pubertal donors revealed that younger donors had more signs of atresia after the same period of coasting. We found different follicular dynamics following coasting in younger donors. It is possible that younger donors are less capable to sustain follicular survival most likely due to insufficient luteinizing hormone signaling. In summary, the pre-pubertal status influences follicular dynamics and reduces the oocyte developmental competence curve following OS and FSH withdrawal in heifers.

Reproduction (2018) 156 239-248
\end{abstract}

\section{Introduction}

The manipulation of reproductive hormones requires knowledge of ovarian physiology, which is mainly based on a network of extracellular and intracellular molecular interactions controlled by follicle-stimulating hormone (FSH) and luteinizing hormone (LH). One of the functions of FSH is the tonic stimulation of granulosa cells via its receptor FSHR, which increases intracellular CAMP formation and activation of genes required for proliferation and differentiation (Hillier 2001). Then, tonic stimulation of granulosa cells from dominant follicles by LH via its receptor LHR prior to its surge mimics some of the FSH actions while its surge triggers ovulation (Hillier 2001, Nivet et al. 2017). Therefore, the fate of follicles is based on the granulosa cell responses to circulating hormones (Matsuda et al. 2012). Understanding these interactions is crucial to define new approaches for pharmaceutical manipulation of ovarian function and to improve fertility treatments.

In cattle, assisted reproductive technologies such as in vitro fertilization and embryo transfer were created and have been used for animals of high commercial value. One important discovery that has significantly increased embryo yields in dairy cows is ovarian stimulation (OS) followed by $\mathrm{FSH}$ withdrawal, also known as coasting (Sirard et al. 1999, Blondin et al. 2002). This technique is based on the maintenance of a high concentration of gonadotropin by injection of exogenous FSH for 3 days followed by a period of time with no exogenous FSH before the ovum pick-up (OPU) procedure. During this time, a temporary improvement in oocyte developmental competence generally occurs (Nivet et al. 2012). Indeed, the final oocyte competence acquisition occurs between the FSH decline and the pre-ovulation $\mathrm{LH}$ surge artificially induced by coasting (Sirard et al. 2006). Interestingly, oocyte quality increases at the beginning of coasting, then reaches a maximum after 2 days and plateaus, and then decreases as the follicle begins to undergo atresia and late differentiation (Nivet et al. 2012). However, coasting dynamics and the quality of oocytes following coasting vary significantly between animals and according to their sexual maturity (Landry et al. 2016, 2017).

Although OS is possible in peri-pubertal or even pre-pubertal heifers, it is well documented that 
embryo yields are significantly lower compared to sexually mature cows (Gandolfi et al. 1998, Salamone et al. 2001, Kauffold et al. 2005, Landry et al. 2016). Multiple essential biological functions such as cell differentiation, cell survival and death, inflammation and apoptosis signaling are affected in peri-pubertal heifers (Landry et al. 2017). Knowing that basal LH is lower before puberty and gradually increases as heifers reach puberty (Rodriguez \& Wise 1989, Day \& Nogueira 2013), it was proposed that the unsatisfactory reproduction rates in peri-pubertal heifers is possibly related to the insufficiency in LH signaling (Landry et al. 2017). To support this concept, it is possible to identify a number of genes that were associated with atresia and late differentiation in previous studies (Nivet et al. 2013, Douville \& Sirard 2014, Girard et al. 2015). By performing a meta-analysis of transcriptomic data from optimal and late differentiated and atretic follicles, we discovered a number of potential biomarkers to assess the follicular status during coasting. These targets were validated on granulosa cell samples from animals of different ages and different coasting times to test the hypothesis. We found that, indeed, insufficient LH signaling in younger donors during coasting forces follicles to undergo atresia much sooner compared to follicles from sexually mature cows during the same period of coasting. Thus, the optimal window of oocyte competence following coasting is reduced and moved earlier in time.

\section{Materials and methods}

\section{Ethics statement}

The clinical procedures and industrial practices used at Boviteq follow the established cattle reproduction management practices, which have been approved by the College of Veterinary Surgeons of Quebec (OMVQ), the Canadian Embryo Transfer Association, and the International Embryo Transfer Society. This company follows the Canadian Council on Animal Care guidelines for farm animals and the research projects do not involve the use of exclusive animals for research purposes or the implementation of new animal procedures, other than the ones used in their routine commercial activities, to obtain additional biological samples. This study did not require handling animals on university premises.

\section{Data retrieval}

Microarray gene expression data from earlier studies of granulosa cells (Gene Expression Omnibus number: GSE110578, GSE40916, GSE63904, GSE63918, GSE63919 and GSE56145) were retrieved from the ELMA database and pooled together for meta-analysis. All datasets were generated using the EmbryoGENE bovine microarray and were analyzed using the following contrasts: heifers with low blastocyst yields vs cows with optimal blastocyst yields, 44 vs $92 \mathrm{~h}$, and 68 vs $92 \mathrm{~h}$ of FSH withdrawal, plateau vs atretic follicles of $6-9 \mathrm{~mm}$ and $>9 \mathrm{~mm}$ in diameter. All microarray experiments were validated in the original studies (Nivet et al. 2013, Douville \& Sirard 2014, Girard et al. 2015). The data from each microarray were subjected to a simple background subtraction, normalized within array (Loess) and between array (Quantile), and analyzed statistically with the Limma package using FlexArray 1.6.1 (http://genomequebec.mcgill.ca/FlexArray).

\section{Meta-analysis of biomarkers of atresia}

Microarray meta-analysis was performed using the vote counting method (Tseng et al. 2012, Rikke et al. 2015). Briefly, differentially expressed (DE) genes are first selected based on a threshold to obtain a list of DE genes from each study. The vote for each gene is then calculated as the total number of times it occurs in all DE lists, and the final DE genes are selected based on the minimal number of votes set by the user. In this study, DE genes with a threshold $P$ value lower than 0.1 from five different arrays were used in the vote counting meta-analysis. The vote counting strategy used in this study ranked biomarkers on the basis of one principal and two secondary criteria. The principal criterion was the number of supporting studies in which each microarray showed significant differential expression in the same direction for a given biomarker, and this counted as a vote in favor of that biomarker being real. Because vote counting frequently leads to ties, we also used two secondary criteria. One being that the first vote should be from the study contrasting good (over $70 \%$ embryo yield) and poor donors (lower than 35\% embryo yield), in order to find biomarkers that are expressed in poor donors and in association with different stages of atresia. The second was the computation of a simple fold change average between all counts for a given biomarker to differentiate the most promising ones in the full set. The vote counting method was previously tested and approved as a strategy to rank biomarker candidates and is indeed an effective method for selecting biomarkers (Rikke et al. 2015).

\section{Analysis of biological functions and upstream regulators}

In order to determine which biological functions were affected by the candidate biomarkers, the meta-analysis datasets were subjected to functional analysis using Ingenuity Pathway Analysis (IPA). Briefly, the lists of differentially expressed genes from the meta-analysis were uploaded into IPA and analyzed for major biological functions and potential upstream regulators. This attributed the probability of association between DE genes in the datasets and major biological functions affected. Also, IPA determines the upstream regulators of DE genes by referring to its database of previously known effects of different molecules (endogenous or exogenous) on target genes. Each upstream regulator has an overlap $P$ value and an activation $Z$ score. The activation $Z$ score is an overall score based on the known effects (upregulation or downregulation) of a molecule on each of its target genes. An upstream regulator is thus attributed an activated ( $Z$ score $>2$ ), inhibited ( $Z$ score $<-2$ ) or uncertain state based on the observed changes in gene expression of known downstream targets. This analysis enabled 
us to identify major upstream regulators as a consequence of follicular atresia.

\section{OS treatment and granulosa cell collection}

Samples were obtained according to a previously published study protocol of embryo production from Holstein Bos Taurus (Landry et al. 2016). Briefly, each animal was first treated with progesterone (Zoetis, Parsippany-Troy Hills, NJ, USA) in order to reduce the risk of spontaneous ovulation. All large follicles (superior or equal to $5 \mathrm{~mm}$ ) were aspirated $36-48 \mathrm{~h}$ prior to administration of hormones. The OS program consisted of six injections of NIH Folltropin-V (Bioniche Animal Health, Belleville, ON, Canada) administered at 12-h intervals. According to animal age, body weight and/or based on previous stimulations, FSH was administered in five $30 \mathrm{mg}$, six $30 \mathrm{mg}$ or six $40 \mathrm{mg}$ doses of NIH Folltropin- $\mathrm{V}$, followed by a coasting (no FSH) period of 30 or $43 \mathrm{~h}$. Using transvaginal ultrasonography, follicular diameters were measured and cumulus-oocyte complexes (COCs) were collected by transvaginal puncture under epidural anesthesia (COOK Medical, Bloomington, IN, USA) using an 18-G needle and COOK aspiration unit (COOK Medical). Granulosa cells and COCs were collected in warm HEPES-buffered Tyrode's medium (TLH) containing Hepalean (10 IU/mL). After removing the oocytes and cumulus, granulosa cells were purified by centrifugation (1800 $\mathrm{g}$ RPM for $1 \mathrm{~min}$ ) and the cell pellets were snap frozen on dry ice before RNA extraction. The OPU procedure was performed in a commercial IVF setting, namely at Boviteq (Saint-Hyacinthe, QC, Canada), a center specialized in bovine embryo transfer and other assisted reproduction technologies involved in research and development.

\section{RNA extraction}

Total RNA was extracted from granulosa cells from 32 heifers and 28 cows using the RNeasy mini kit (Qiagen), following the protocol recommended by the manufacturer. Total RNA integrity and concentration were evaluated using an Agilent 2100 Bioanalyzer (Agilent Technologies) with the RNA NanoLab Chip (Agilent Technologies). All extracts were of good quality with RNA integrity numbers higher than 8.9.

\section{Complementary DNA preparation and quantitative real- time polymerase chain reaction}

To confirm the microarray analysis results, quantitative realtime polymerase chain reaction (qRT-PCR) was performed on cDNA. Briefly, RNA (325 ng) from granulosa cells (all samples) was reverse-transcribed using a qScript Flex cDNA Synthesis Kit (Quanta Biosciences, Gaithersburg, MD, USA) with a mixture of oligo dT and random primers according to the manufacturer's recommendations. The primers used for qRT-PCR are listed in (Supplementary Table 1, see section on supplementary data given at the end of this article) and were designed using the IDT PrimerQuest tool (http://www.idtdna. com/primerquest/home/index) from sequences obtained using Bos taurus (taxid: 9913) reference RNA sequences (refseq_rna) and results from our meta-analysis. To confirm the specificity of each pair of primers, electrophoresis on a standard $1.2 \%$ agarose gel was performed for each amplified fragment. The PCR products were then purified with the QIAquick PCR purification kit (Qiagen), quantified using the NanoDrop ND-1000 and sequenced. The products were then used to create standard curves for quantification experiments, with dilutions ranging from $2 \times 10^{-4}$ to $2 \times 10^{-8} \mathrm{ng} / \mathrm{nL}$. Real-time PCR was performed on a LightCycler 480 (Roche Diagnostics, Laval, QC, Canada) using SYBR incorporation in order to analyze gene expression stability in the two groups of granulosa cells (heifers with $30 \mathrm{~h}$ of coasting vs cows with $30 \mathrm{~h}$ of coasting; heifers with $43 \mathrm{~h}$ of coasting vs cows with $43 \mathrm{~h}$ of coasting). Each qRT-PCR reaction, in a final volume of $10 \mu \mathrm{L}$, contained the complementary DNA, $0.25 \mathrm{mM}$ of each primer and 1X SYBR mixture (LightCycler 480 SYBR Green I Master, Roche Diagnostics). The PCR conditions used for all genes were as follows: denaturing for $10 \mathrm{~min}$ at $95^{\circ} \mathrm{C}$; $50 \mathrm{PCR}$ cycles (denaturing, $95^{\circ} \mathrm{C}$ for $10 \mathrm{~s}$; annealing (Supplementary Table 2) for $10 \mathrm{~s}$; extension, $72^{\circ} \mathrm{C}$ for $20 \mathrm{~s}$ ), a melting curve $\left(95^{\circ} \mathrm{C}\right)$ and a final cooling step at $40^{\circ} \mathrm{C}$. Complementary DNA quantifications were performed using LightCycler 480 software version 1.5 (Roche Diagnostics) by comparison with the standard curves. PCR specificity was confirmed by melting-curve analysis provided by the LightCycler software. The data were normalized through geNORM, and the most stable reference genes were identified by the stepwise exclusion of the least stable gene and recalculating the $M$ values. Four housekeeping genes, namely B-actin (ACTB), glyceraldehyde-3-phosphate dehydrogenase (GAPDH), splicing factor 3 subunit 1 (SF3A1) and TATA-Box binding protein were found to be the most stable genes with $M$ values $\leq 1.5$ as recommended by the software to normalize our data. Normalized data were cleaned using the Rout method of outlier removal and were analyzed using unpaired $T$ test in order to establish significance. Differences were considered to be statistically significant at the $95 \%$ confidence level $(P<0.05)$. Values are presented as mean \pm S.E.M. All statistical analyses were performed using Graphpad Prism, version 7.00 (GraphPad software).

\section{Results}

Using the vote counting method, we performed transcriptome meta-analyses of four independent microarray studies (five microarray datasets in total). Each individual array analyzed a different follicular status from the optimal period toward follicular atresia. The DE genes were proposed as potential biomarker candidates and were submitted to functional analysis within IPA and validation by real-time PCR.

In order to explore the effects of coasting time in young and older donors, data from 331 dairy cattle subjected to $\mathrm{OS}$ and coasting were randomly selected and divided into two groups based on age : 170 pre-pubertal heifers (ages from less than 10 months) and 161 post-pubertal heifers (ages between 12 and 18 months). There was no significant difference between the blastocyst rates of preand post-pubertal animals. However, the duration of 
A

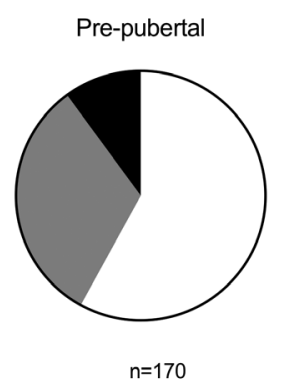

B

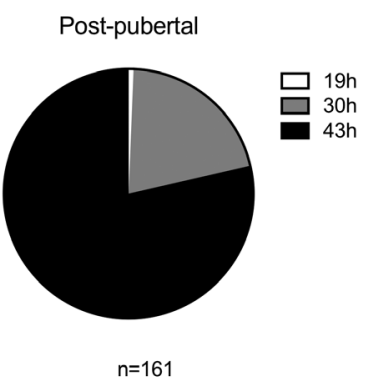

C

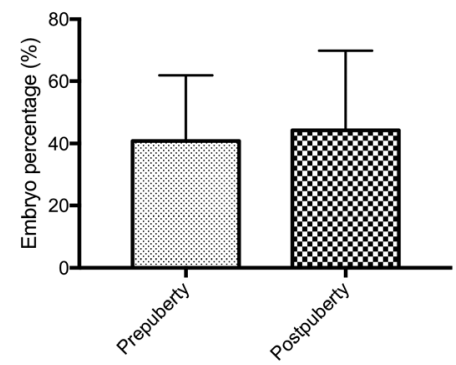

Figure 1 Relationship between oocyte donor age and coasting period length during ovarian stimulation regimens for (A) 170 pre-pubertal heifers and (B) 161 post-pubertal cows. For the same animals, (C) mean embryo percentages 7 days following in vitro fertilization of all oocytes matured. coasting period required to achieve the same blastocyst yield in the two groups was significantly different (chi-square $<0.0001$ ) (Fig. 1).

\section{Meta-analysis}

Our hypothesis suggests that younger donors have a lower capability to sustain follicle growth during FSH withdrawal and this leads to follicular atresia. Thus, we compared the DE genes of a total of four microarrays that specifically compared granulosa cells from the optimal coasting period to granulosa cells from late differentiation, and granulosa cells from plateau follicles to granulosa cells from atretic follicle of $6-9 \mathrm{~mm}$ and $>9 \mathrm{~mm}$ diameter. Using a vote counting meta-analysis in order to identify potential biomarkers, a total of 193 differentially expressed genes (DEGs) were significantly associated with late follicle differentiation and/or atresia in young donors (Supplementary Table 2). A summary of the 30 most DEGs are shown in Table 1.

\section{Functional analysis}

Using the datasets of modulated genes from the metaanalysis above, IPA revealed a significant association between a group of genes expressed differentially in granulosa cells and certain biological functions. The latter include cell death and survival, cellular development, connective tissues development and cellular growth and proliferation (Fig. 2). In addition, IPA generated statistically significant predictions for increased ( $Z$ score $>2$ ) or decreased ( $Z$ score $<-2$ ) activity of upstream transcriptional regulators that are the most activated or inhibited (Table 2A) and the most significant (Table 2B) in association with the average fold change of the DE genes from the meta-analysis.

\section{Validation of meta-analysis gene expression}

Confirmation of the microarray and meta-analysis results was obtained in the form of real-time qPCR data for transcripts selected on the basis of differential expression in the poor pre-pubertal donors and on the basis of the meta-analysis. Six candidate biomarkers were selected according to the difference in their expression levels compared to the optimal condition and their relevance in follicular atresia: Mitochondria-localized glutamic acid-rich protein (MGARP) also known as the ovaryspecific acidic protein (OSAP), Gasdermin B (GSDMB), creatine kinase brain isoform $(C K B)$, potassium channel tetramerization domain containing 8 (KCTD8), cysteinerich secretory protein $\mathrm{LCCL}$ domain containing 2 (CRISPLD2) and inhibin A (INHA) (Fig. 3). The expression

Table 1 The top 15 most downregulated genes and the top 15 most upregulated genes in the meta-analysis of granulosa cells are shown with their average fold change and $P$ value. A complete list of DEGs is available in Supplementary Table 2.

\begin{tabular}{lcclcc}
\hline Gene symbol & Average FC & Average $\boldsymbol{P}$ value & Gene symbol & Average FC & Average $\boldsymbol{P}$ value \\
\hline CALB2 & -3.80 & 0.0287743 & SH3RF1 & 2.37 & 0.0212858 \\
NMB & -3.17 & 0.0083525 & FOLR2 & 2.38 & 0.0395062 \\
INHA & -2.90 & 0.0223478 & CLCA2 & 2.40 & 0.0393079 \\
SUSD4 & -2.62 & 0.0214671 & CKB & 2.41 & 0.0235166 \\
GSTA5 & -2.51 & 0.0298568 & DEFB4 & 2.41 & 0.0096596 \\
TBC1D8 & -2.39 & 0.0154918 & GSDMB & 2.46 & 0.0261716 \\
GRB14 & -2.36 & 0.0277227 & ETS2 & 2.52 & 0.0166111 \\
OSAP & -2.34 & 0.0205689 & CD5L & 2.74 & 0.0355574 \\
ECRG4 & -2.27 & 0.0171964 & SWAP70 & 2.77 & 0.0571574 \\
NAP1L5 & -2.22 & 0.0092056 & IL1A & 2.96 & 0.0040150 \\
CITED1 & -2.21 & 0.0052008 & CTSS & 3.26 & 0.0236380 \\
TOX2 & -2.20 & 0.0268395 & PLAT & 3.60 & 0.0300998 \\
LRRC17 & -2.19 & 0.0158701 & TRIB1 & 3.70 & 0.0242082 \\
CRISPLD2 & -2.12 & 0.0547113 & DEFB5 & 3.76 & 0.0253889 \\
FDFT1 & -2.06 & 0.0070817 & FABP4 & 4.02 & 0.0304273 \\
\hline
\end{tabular}




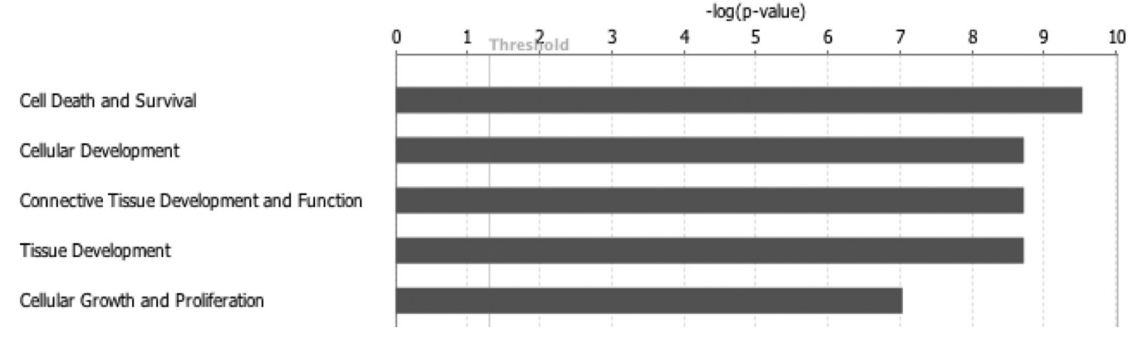

Figure 2 The five most significant biological functions from the meta-analysis datasets of the differentially expressed genes (DEGs) in granulosa cells associated with follicle late differentiation and atresia. The threshold line represents the significant $P$ value. patterns of all candidate genes were consistent with the meta-analysis results.

\section{Discussion}

The results of this study showed that pre-pubertal donors have different follicular dynamics following FSH withdrawal and reach follicular atresia sooner than post-pubertal donors. With the accumulation of transcriptomic data from microarray experiments, it was possible to use meta-analysis to further investigate the transcriptional regulation of genes across multiple studies and obtain biologically significant information (Tseng et al. 2012). Using the vote counting method for meta-analysis of DEGs (Rikke et al. 2015), we compared granulosa cells from optimal follicles to granulosa cells from late differentiated and atretic follicles in superstimulated cows.

Interestingly, embryo rates from pre-pubertal animals, younger than 8 months of age, increased significantly (from $30 \%$ to $40 \%$ blastocysts) over the last few years (Landry et al. 2016, 2017 and this paper), and this is a reflection of the empirical adaptation of coasting time. We previously demonstrated that oocytes originating

Table 2 Upstream regulator analysis on the datasets from the granulosa cell's meta-analysis.

\begin{tabular}{|c|c|c|c|c|}
\hline Upstream regulator & Molecule type & Predicted activation state & Activation $Z$ score & $P$ Value of overlap \\
\hline \multicolumn{5}{|l|}{ (A) Most activated } \\
\hline$N F K B$ & Complex & Activated & 2.183 & $1.45 E-01$ \\
\hline CXCL12 & Cytokine & Activated & 2.000 & 2.59E-02 \\
\hline STAT1 & Transcription regulator & & 1.982 & $1.33 E-01$ \\
\hline$I L 1 A$ & Cytokine & & 1.965 & 4.73E-02 \\
\hline IL6 & Cytokine & & 1.942 & $6.06 E-02$ \\
\hline$I L 1 B$ & Cytokine & & 1.913 & $7.56 \mathrm{E}-04$ \\
\hline CSF2 & Cytokine & & 1.912 & $5.46 \mathrm{E}-03$ \\
\hline CREB 1 & Transcription regulator & & 1.890 & $1.41 \mathrm{E}-02$ \\
\hline$A P P$ & Other & & 1.769 & $2.24 \mathrm{E}-04$ \\
\hline TLR4 & Transmembrane receptor & & 1.756 & $5.49 \mathrm{E}-03$ \\
\hline$T N F$ & Cytokine & & 1.629 & $6.61 \mathrm{E}-05$ \\
\hline IFNG & Cytokine & & 1.616 & $1.78 \mathrm{E}-03$ \\
\hline$A H R$ & Ligand-dependent NR & & -1.741 & $1.40 \mathrm{E}-02$ \\
\hline Progesterone & Chemical-endogenous & & -1.757 & $2.78 \mathrm{E}-03$ \\
\hline PSEN1 & Peptidase & & -1.969 & 7.53E-03 \\
\hline \multicolumn{5}{|l|}{ (B) Most significant } \\
\hline$\beta$-Estradiol & Chemical-endogenous mammalian & & 0.993 & $9.24 \mathrm{E}-07$ \\
\hline VEGF & Group & & -0.786 & $3.05 \mathrm{E}-05$ \\
\hline$T N F$ & Cytokine & & 1.629 & $6.61 \mathrm{E}-05$ \\
\hline TP53 & Transcription regulator & & 0.623 & 8.87E-05 \\
\hline HRAS & Enzyme & & & $1.25 \mathrm{E}-04$ \\
\hline$A P P$ & Other & & 1.769 & $2.24 \mathrm{E}-04$ \\
\hline ACKR1 & g-Protein coupled receptor & & & $2.56 \mathrm{E}-04$ \\
\hline VEGFA & Growth factor & & 0.818 & $3.13 \mathrm{E}-04$ \\
\hline HIC1 & Transcription regulator & & 0 & 4.07E-04 \\
\hline IL10RA & Transmembrane receptor & & -0.788 & 4.07E-04 \\
\hline ESR1 & Ligand-dependent nuclear receptor & & 0.612 & $4.34 \mathrm{E}-04$ \\
\hline FSH & Complex & & & $5.27 \mathrm{E}-04$ \\
\hline HNF1B & Transcription regulator & & -0.152 & $6.01 \mathrm{E}-04$ \\
\hline$L H$ & Complex & & & 7.51E-04 \\
\hline$I L 1 B$ & Cytokine & & 1.913 & $7.56 \mathrm{E}-04$ \\
\hline
\end{tabular}

(A) Most activated and (B) most significant upstream regulators. For each upstream regulator, molecule type, predicted activation state, $Z$ score and statistical significance ( $P$ value of overlap between the dataset and the genes that are regulated by the upstream regulator) are shown in the table. Italics indicates non-significant. 

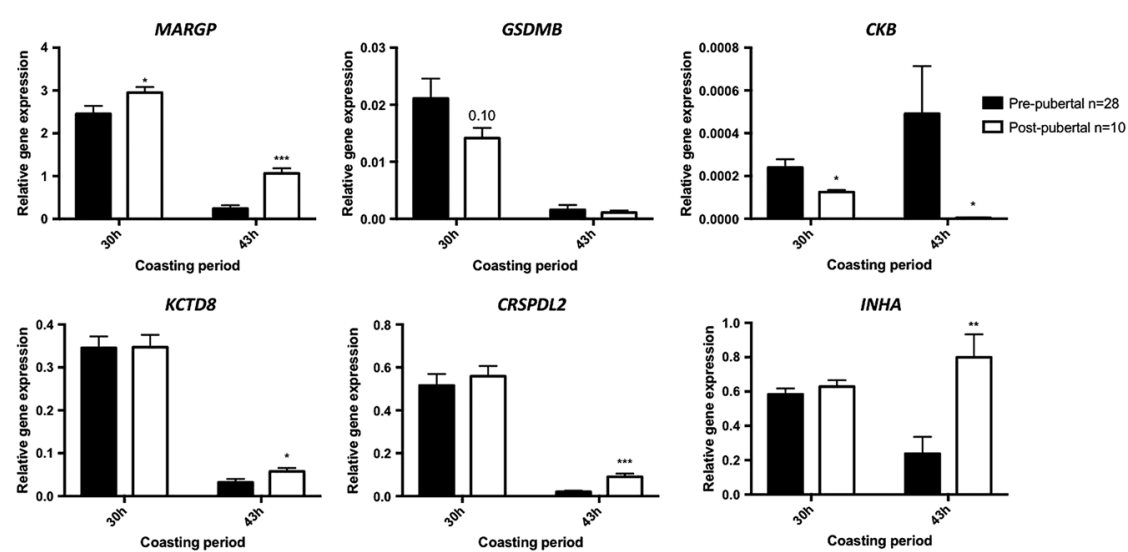

Figure 3 Gene expression levels of six selected biomarkers were used to assess the atresia level at $30 \mathrm{~h}$ and $43 \mathrm{~h}$ of coasting in pre- and post-pubertal bovine granulosa cells. RT-qPCR values are mean relative expression with standard error of the mean compared to the reference groups (black bar). Significant differences were calculated using unpaired $T$ test $\left(* P<0.05,{ }^{* *} P<0.01,{ }^{* * *} P<0.001\right.$, $* * * * P<0.0001)$. from heifers younger than 10 months of age are less competent compared to oocytes from sexually mature cows (Landry et al. 2016). Before the use of coasting, many studies demonstrated that bovine embryos could be produced successfully in vitro using oocytes from sexually immature animals (Majerus et al. 1999, Palma et al. 2001) but with a significant reduction in embryos yields (Revel et al. 1995, Presicce et al. 1997, Khatir et al. 1998). In the present study, the embryo yield was similar between pre- and post-pubertal cows. However, the coasting period was significantly different between the two groups, suggesting that a shorter period of FSH withdrawal in pre-pubertal animal results in different follicle dynamics and a better embryo outcome. Our meta-analysis may explain the differences as we found DEGs between optimal and late differentiation and atretic follicles that characterize the follicle status in pre- and post-pubertal animals.

\section{Gene analysis}

In this study, the genes were analyzed in a standard contrast between pre- and post-pubertal oocyte donors. In this context, depending on the selected biomarkers, they can be associated with optimal timing or late differentiation and atresia. The mitochondria-localized glutamic acid-rich protein (MGARP), also known as the OSAP, is upregulated in dominant follicles (Liu et al. 2009). Although the detailed regulatory mechanisms are not yet fully understood, it is known that MGARP is a mitochondrial transmembrane protein that operates during steroidogenesis (Matsumoto et al. 2009). It was proposed that MGARP functions as a transporter for the precursors of steroidogenesis and/or helps the newly synthesized steroids exit mitochondria (Zhou et al. 2011). Moreover, its expression increased in the same proportion as sex hormone levels (Zhou et al. 2011). This association of MGARP with steroidogenesis is consistent with our data demonstrating its downregulation in atretic follicles and its association with lower progesterone production as predicted by IPA.
The gene encoding for cysteine-rich secretory protein LCCL domain containing 2 (CRISPLD2) is also regulated by progesterone as its expression was significantly increased following progesterone injection in mice (Sriraman et al. 2010, Yoo et al. 2014). Moreover, the suppression of CRISPLD2 was associated with the downregulation of some important extracellular matrix genes (Zhang et al. 2016), which suggests a potential role in the regulation of the ECM enzymes and proteins following the increase in progesterone. Interestingly, CRISPLD2 also inhibited inflammation by the modulation of interleukin IL1-B and IL6 (Zhang et al. 2016). The lack of CRISPLD2 expression contributes to the increase in inflammation and potentially the increase in ROS since atresia is an inflammatory process of cellular death. This suggests that after the same time of coasting, younger donors are more advanced in atresia signaling compared to mature cows.

The inhibins (inhibin $A$ and inhibin B) are glycoprotein hormones from the transforming growth factor B (TGF-B) family. Inhibin A (INHA) is mainly secreted by differentiated granulosa cells under LH during the preovulatory phase (Welt et al. 1999, Welt \& Schneyer 2001) while inhibin B (INHB) is secreted by developing granulosa cells (Broekmans et al. 2009). The expression of INHA was detected in granulosa cells from dominant follicles and in the corpus luteum, but not in small antral follicles (Schwall et al. 1990). Thus, the level of INHA depends on gonadotropin stimulation and on the stage of follicle development (Welt \& Schneyer 2001). The expression of INHA decreased faster (at $43 \mathrm{~h}$ of coasting) in young animals, supporting the hypothesis of a potential lack of $\mathrm{LH}$ action. Taken together, these results suggest that in younger donors, the absence of progesterone, potentially due to the lack of LH signaling, downregulate essential genes that control steroidogenesis and inflammation, leading to the promotion of cellular death and atresia.

Younger donors also expressed multiple atresia biomarkers. The creatine kinase (CK), brain isoform $(\mathrm{CKB})$ is a fundamental enzyme for cellular energy due 
to its mechanism of storing, buffering and transporting high-energy phosphates from the mitochondria to places that require energy (Zervou et al. 2017). The apoptosis process can be ATP dependent or not, but most commonly, follicular atresia occurs by caspase activation, an ATP-dependent process (Tsujimoto 1997). Based on the high demand of ATP for atresia and the fundamental role of $C K B$ in the maintenance of cellular energy, we can suggest that CKB levels are expected to be increased in atretic follicles. Moreover, a recent study demonstrated higher expression of $C K B$ in pre-pubertal donors compared to post-pubertal cows (Landry et al. 2017). Similarly, the potassium channel tetramerization domain 8 (KCTD8) gene is part of a voltage-gated potassium channel that affects the permeation of potassium $(\mathrm{K}+)$ through the channel pore (Paus et al. 2012). A reduction of intracellular levels of $\mathrm{K}+$ may be one of the permissive signals for apoptosis (Yu 2003). Low intracellular K+ decreased the DNA-binding activity of anti-apoptotic transcription factors and increased the binding activity of the proapoptotic transcription factors (p53 and forkhead) (Yang et al. 2006). Several classes of potassium channels are expressed in granulosa cells (Mason et al. 2002, Traut et al. 2009), and it was previously suggested that the loss of potassium in oocytes and granulosa cells may be involved in initiating the cascade of events leading to their demise (Perez et al. 2000). Suppressing the potassium efflux in whole cells prevents the activation of the nuclease and caspase activity whereas enhancing the efflux of $\mathrm{K}+$ activates those apoptotic enzymes (Hughes and Cidlowski, 1999). This suggests that a lower level of KCTD8 would reduce the intracellular level of $\mathrm{K}+$ by modulating its permeability in granulosa cells and may lead the follicle to atresia in pre-pubertal donors. On the other hand, it is possible that a high concentration of KCTD8 prevents atresia in older animals by conserving normal level of $\mathrm{K}+$ in granulosa cells.

Gasdermin B (GSDMB) is one of the four members of the Gasdermin family and plays a role in the regulation of epithelial proliferation by acting as a tumor suppressor (Hergueta-Redondo et al. 2014). Interestingly, GSDMB is a regulator of TGF-B1 expression, which has dual functions with a role in granulosa cell proliferation, differentiation and apoptosis (Kale et al. 2013). We suggest that GSDMB is an important mediator of cellular death in granulosa cells and its expression increases apoptotic signals and TGFB to move the follicle toward atresia.

\section{Functional analysis}

We also performed functional analysis of the DE gene dataset to describe the biological functions and the upstream regulators associated with the follicle demise. One of the most important factors in folliculogenesis is the balance between cell survival and cell death. It comes to no surprise that biological functions such as cell death and survival, cellular development, growth and proliferation were modulated during granulosa cell late differentiation and atresia. Indeed, apoptosis signaling plays a critical role in the maintenance of the ovarian function in order to remove most follicles that are not suited for ovulation. The first sign of atresia is the initiation of apoptosis in mural granulosa cells, which involves both intrinsic and extrinsic signaling (Carou et al. 2017). A complete description of apoptotic pathways in granulosa cells is not available yet, but a spectrum of pro- and anti-apoptosis molecules are finely regulated by hormones such as gonadotropins, growth factors, cytokines and estrogens (Matsuda et al. 2012). Interestingly, the upstream regulator analysis revealed some potential modulators of atresia.

The initiation of follicular atresia is orchestrated by the depletion of key survival-promoting factors and/or by specific death ligand molecules (Matsuda-Minehata et al. 2006). In granulosa cells, estradiol is produced by the aromatase under FSH and has various actions such as promoting folliculogenesis and inhibiting cell apoptosis (see review Rosenfeld et al. 2001). We believe that the decline in FSH and estradiol before the LH surge is a trigger for the initiation of follicle differentiation (Sirard et al. 2006). Thus, the follicle produces cytokines in order to increase inflammation and vascularization, which are activated similarly in early apoptosis (Hatzirodos et al. 2014). If the LH receptor is expressed in the dominant follicle, the LH surge will trigger differentiation and ovulation. On the other hand, the absence of LHR and/ or LH signaling will push the follicle toward atresia following a progressive depletion of survival factors

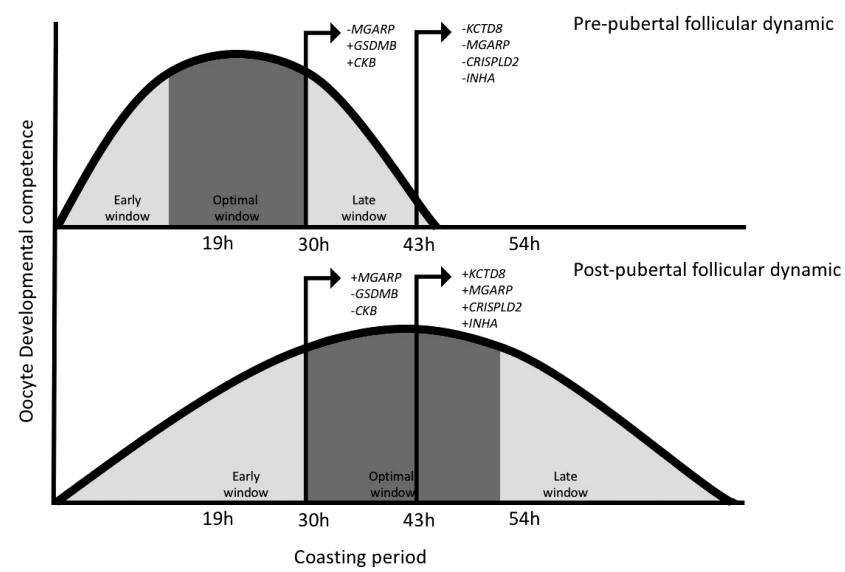

Figure 4 Schematization of follicle dynamics following coasting in pre- and post-pubertal donors. The oocyte developmental competence is represented by the black curve across the coasting period. Each specific phase of follicle dynamics is described inside the curve as follows: early, optimal and late windows of oocyte developmental competence. The arrows represent the expression of the selected biomarkers, a plus or negative (+/-) sign represents an increase or decrease in gene expression compared to the other group for the same period of coasting. 
initiated by FSH, estradiol and/or basal LH. Follicle atresia was increased in cows treated with an antagonist to $\mathrm{GnRH}$ (Cetrotide) that removes basal $\mathrm{LH}$ during $\mathrm{FSH}$ withdrawal (Nivet et al. 2017), suggesting a crucial role of basal $\mathrm{LH}$ in follicle survival. It is interesting to notice that early signs of atresia have a positive effect on oocyte developmental competence (Sirard et al. 1999, Vassena et al. 2003), which is characteristic of the first step in the initiation of follicle differentiation following $\mathrm{FSH}$ decline or withdrawal (Sirard et al. 2006).

Follicular atresia is also induced by death ligandreceptors such as the tumor necrosis factor (TNF) signaling (Matsuda et al. 2012, Yamamoto et al. 2015). In a recent meta-analysis, we determined that TNF is an important regulator of cell differentiation not only associated with optimal oocyte developmental competence but also associated with atresia in follicle persistence (Landry et al. 2018). Indeed, TNF is a multifunctional proinflammatory cytokine that mediates a wide range of biological functions by binding to two specific receptors (type I and II). Type I receptor contains an intracellular death domain and type II induces gene expression, cell survival, growth and differentiation (Sakumoto et al. 2003). TNF plays a broad role during the preovulatory period as it induced ovulation in perfused rat ovaries and the effect was further increased by the addition of LH (Brännström et al. 1995). On the other hand, TNF expression was increased to promote the demise of unruptured follicles (Yamamoto et al. 2015), necrosis being the result of an inflammatory reaction (Yang et al. 2015). However, inflammation also plays a role during folliculogenesis as it is well accepted that mammalian ovulation is comparable to an inflammatory reaction (Jabbour et al. 2009). In this study, we showed that atresia involves multiple cytokines inducing inflammation. The follicle persistence without LH surge may cause an inflammatory cascade through the non-canonical pathway of NF-kB, which stimulates the production of pro-inflammatory cytokines such as IL-1B, IL6, INFG and angiogenesis factors (Machelon \& Nome 1999, Bhattacharyya et al. 2010, Santulli et al. 2015, Yang et al. 2015) that modulate follicular regression.

\section{Conclusion}

The FSH decline before the $\mathrm{LH}$ surge plays a crucial role during oocyte developmental competence acquisition, which can be reproduced artificially by FSH withdrawal. However, we showed that pre- and post-pubertal cows have different dynamics following coasting (Fig. 4) and younger donors are less capable of sustaining follicular survival, most likely due to their lack in LH signaling. Thus, it is recommended that FSH withdrawal be shorter in younger donors in order to achieve higher blastocyst rates. Moreover, we provided a set of new biomarkers that will help to characterize the follicular status of atresia in bovine granulosa cells. Those biomarkers will provide new insight in the evaluation of OS regimens.

\section{Supplementary data}

This is linked to the online version of the paper at https://doi.org/10.1530/REP-18-0186.

\section{Declaration of interest}

The authors declare that there is no conflict of interest that could be perceived as prejudicing the impartiality of the research reported.

\section{Funding}

The Natural Sciences and Engineering Research Council of Canada - Collaborative Research and Development (NSERCCRD grant no. RDCPJ461697-13) provided funding for this study. D A Landry received studentship support from NSERC and REDIH (CIHR Training program in Reproduction, Early Development, and Impact on Health). L R-P received a studentship support from ELAP (Emerging Leader in the Americas Program).

\section{Acknowledgement}

The authors would like to thank Boviteq for allowing the use of granulosa cells and data from their heifers and cows.

\section{References}

Bhattacharyya S, Dudeja PK \& Tobacman JK 2010 Tumor necrosis factor $\alpha$-induced inflammation is increased but apoptosis is inhibited by common food additive carrageenan. Journal of Biological Chemistry 285 39511-39522. (https://doi.org/10.1074/jbc.M110.159681)

Blondin P, Bousquet D, Twagiramungu H, Barnes F \& Sirard M-A 2002 Manipulation of follicular development to produce developmentally competent bovine oocytes. Biology of Reproduction 66 38-43. (https:// doi.org/10.1095/biolreprod66.1.38)

Brännström M, Bonello N, Wang LJ \& Norman RJ 1995 Effects of tumour necrosis factor alpha (TNF alpha) on ovulation in the rat ovary. Reproduction, Fertility, and Development 7 67-73.

Broekmans FJ, Soules MR \& Fauser BC 2009 Ovarian aging: mechanisms and clinical consequences. Endocrine Reviews 30 465-493. (https://doi. org/10.1210/er.2009-0006)

Carou MC, Cruzans PR, Maruri A, Farina MG, Fiorito CD, Olea G \& Lombardo DM 2017 Apoptosis of bovine granulosa cells: Intracellular pathways and differentiation. Acta Histochemica 119 462-470. (https:// doi.org/10.1016/j.acthis.2017.04.010)

Day ML \& Nogueira GP 2013 Management of age at puberty in beef heifers to optimize efficiency of beef production. Animal Frontiers 3 6-11. (https://doi.org/10.2527/af.2013-0027)

Douville G \& Sirard M-A 2014 Changes in granulosa cells gene expression associated with growth, plateau and atretic phases in medium bovine follicles. Journal of Ovarian Research 7 50. (https://doi.org/10.1186/17572215-7-50)

Gandolfi F, Milanesi E, Pocar P, Luciano AM, Brevini TA, Acocella F, Lauria A \& Armstrong DT 1998 Comparative analysis of calf and cow oocytes during in vitro maturation. Molecular Reproduction and Development 49 168-175. (https://doi.org/10.1002/(SICl)10982795(199802)49:2<168::AID-MRD7>3.0.CO;2-N) 
Girard A, Dufort I, Douville G \& Sirard M-A 2015 Global gene expression in granulosa cells of growing, plateau and atretic dominant follicles in cattle. Reproductive Biology and Endocrinology 13 17. (https://doi. org/10.1186/s12958-015-0010-7)

Hatzirodos N, Hummitzsch K, Irving-Rodgers HF, Harland ML, Morris SE \& Rodgers RJ 2014 Transcriptome profiling of granulosa cells from bovine ovarian follicles during atresia. BMC Genomics 15 40. (https:// doi.org/10.1186/1471-2164-15-40)

Hergueta-Redondo M, Sarrió D, Molina-Crespo Á, Megias D, Mota A, Rojo-Sebastian A, García-Sanz P, Morales S, Abril S, Cano A et al. 2014 Gasdermin-B promotes invasion and metastasis in breast cancer cells. PLOS ONE 9 e90099. (https://doi.org/10.1371/journal.pone.0090099)

Hillier SG 2001 Gonadotropic control of ovarian follicular growth and development. Molecular and Cellular Endocrinology 179 39-46. (https:// doi.org/10.1016/S0303-7207(01)00469-5)

Hughes FM \& Cidlowski JA 1999 Potassium is a critical regulator of apoptotic enzymes in vitro and in vivo. Advances in Enzyme Regulation 39 157-171. (https://doi.org/10.1016/S0065-2571(98)00010-7)

Jabbour HN, Sales KJ, Catalano RD \& Norman JE 2009 Inflammatory pathways in female reproductive health and disease. Reproduction 138 903-919. (https://doi.org/10.1530/REP-09-0247)

Kale AD, Mane DR \& Shukla D 2013 Expression of transforming growth factor $\beta$ and its correlation with lipodystrophy in oral submucous fibrosis: an immunohistochemical study. Medicina Oral, Patologia Oral Y Cirugia Bucal 18 e12-e18. (https://doi.org/10.4317/medoral.18226)

Kauffold J, Amer HAH, Bergfeld U, Weber W \& Sobiraj A 2005 The in vitro developmental competence of oocytes from juvenile calves is related to follicular diameter. Journal of Reproduction and Development $\mathbf{5 1}$ 325-332. (https://doi.org/10.1262/jrd.17002)

Khatir H, Lonergan P, Touzé JL \& Mermillod P 1998 The characterization of bovine embryos obtained from prepubertal calf oocytes and their viability after non surgical embryo transfer. Theriogenology $\mathbf{5 0}$ 1201-1210. (https://doi.org/10.1016/S0093-691X(98)00220-9)

Landry DA, Bellefleur A-M, Labrecque R, Grand F-X, Vigneault C, Blondin P \& Sirard M-A 2016 Effect of cow age on the in vitro developmental competence of oocytes obtained after FSH stimulation and coasting treatments. Theriogenology 86 1240-1246. (https://doi.org/10.1016/j. theriogenology.2016.04.064)

Landry DA \& Sirard MA 2018 Follicle capacitation: A meta-analysis to investigate the transcriptome dynamics following FSH decline in bovine granulosa cells. Biology of Reproduction (https://doi.org/10.1093/biolre/ ioy090)

Landry DA, Labrecque R, Grand F-X, Vigneault C, Blondin P \& Sirard MA 2017 Effect of heifer age on the granulosa cell transcriptome after ovarian stimulation. Reproduction, Fertility and Development $\mathbf{3 0}$ 980-990. (https://doi.org/10.1071/RD17225)

Liu Z, Youngquist RS, Garverick HA \& Antoniou E 2009 Molecular mechanisms regulating bovine ovarian follicular selection. Molecular Reproduction and Development 76 351-366. (https://doi.org/10.1002/ mrd.20967)

Machelon V \& Nome F 1999 Cellular distribution and relative amounts of vascular endothelium growth factor mRNA in granulosa cells from human preovulatory follicles. European Cytokine Network 10 393-402.

Majerus V, De Roover R, Etienne D, Kaidi S, Massip A, Dessy F \& Donnay I 1999 Embryo production by ovum pick up in unstimulated calves before and after puberty. Theriogenology 52 1169-1179. (https://doi. org/10.1016/S0093-691X(99)00209-5)

Mason DE, Mitchell KE, Li Y, Finley MR \& Freeman LC 2002 Molecular basis of voltage-dependent potassium currents in porcine granulosa cells. Molecular Pharmacology 61 201-213. (https://doi.org/10.1124/ mol.61.1.201)

Matsuda F, Inoue N, Manabe N \& Ohkura S 2012 Follicular growth and atresia in mammalian ovaries: regulation by survival and death of granulosa cells. Journal of Reproduction and Development 58 44-50. (https://doi.org/10.1262/jrd.2011-012)

Matsuda-Minehata F, Inoue N, Goto Y \& Manabe N 2006 The regulation of ovarian granulosa cell death by pro- and anti-apoptotic molecules. Journal of Reproduction and Development 52 695-705. (https://doi. org/10.1262/jrd.18069)

Matsumoto T, Minegishi K, Ishimoto H, Tanaka M, Hennebold JD, Teranishi T, Hattori Y, Furuya M, Higuchi T, Asai S et al. 2009 Expression of ovary-specific acidic protein in steroidogenic tissues: a possible role in steroidogenesis. Endocrinology 150 3353-3359. (https://doi. org/10.1210/en.2008-1584)

Nivet A-L, Bunel A, Labrecque R, Belanger J, Vigneault C, Blondin P \& Sirard M-A 2012 FSH withdrawal improves developmental competence of oocytes in the bovine model. Reproduction 143 165-171. (https://doi. org/10.1530/REP-11-0391)

Nivet A-L, Vigneault C, Blondin P \& Sirard M-A 2013 Changes in granulosa cells' gene expression associated with increased oocyte competence in bovine. Reproduction 145 555-565. (https://doi.org/10.1530/REP-13-0032)

Nivet A-L, Vigneault C, Blondin P \& Sirard M-A 2017 Influence of luteinizing hormone support on granulosa cells transcriptome in cattle. Animal Science Journal 89 21-30. (https://doi.org/10.1111/asj.12856)

Palma GA, Tortonese DJ \& Sinowatz F 2001 Developmental capacity in vitro of prepubertal oocytes. Anatomia, Histologia, Embryologia 30 295-300. (https://doi.org/10.1046/j.1439-0264.2001.00324.x)

Paus T, Bernard M, Chakravarty MM, Davey Smith G, Gillis J, Lourdusamy A, Melka MG, Leonard G, Pavlidis P, Perron M et al. 2012 KCTD8 gene and brain growth in adverse intrauterine environment: a genome-wide association study. Cerebral Cortex 22 2634-2642. (https:// doi.org/10.1093/cercor/bhr350)

Perez GI, Maravei DV, Trbovich AM, Cidlowski JA, Tilly JL \& Hughes FM 2000 Identification of potassium-dependent and -independent components of the apoptotic machinery in mouse ovarian germ cells and granulosa cells. Biology of Reproduction 63 1358-1369. (https:// doi.org/10.1095/biolreprod63.5.1358)

Presicce GA, Jiang S, Simkin M, Zhang L, Looney CR, Godke RA \& Yang X 1997 Age and hormonal dependence of acquisition of oocyte competence for embryogenesis in prepubertal calves. Biology of Reproduction 56 386-392. (https://doi.org/10.1095/biolreprod56.2.386)

Revel F, Mermillod P, Peynot N, Renard JP \& Heyman Y 1995 Low developmental capacity of in vitro matured and fertilized oocytes from calves compared with that of cows. Journal of Reproduction and Fertility 103 115-120. (https://doi.org/10.1530/jrf.0.1030115)

Rikke BA, Wynes MW, Rozeboom LM, Barón AE \& Hirsch FR 2015 Independent validation test of the vote-counting strategy used to rank biomarkers from published studies. Biomarkers in Medicine 9 751-761. (https://doi.org/10.2217/BMM.15.39)

Rodriguez RE \& Wise ME 1989 Ontogeny of pulsatile secretion of gonadotropin-releasing hormone in the bull calf during infantile and pubertal development. Endocrinology 124 248-256. (https://doi. org/10.1210/endo-124-1-248)

Rosenfeld CS, Wagner JS, Roberts RM \& Lubahn DB 2001 Intraovarian actions of oestrogen. Reproduction 122 215-226. (https://doi. org/10.1530/rep.0.1220215)

Sakumoto R, Shibaya M \& Okuda K 2003 Tumor necrosis factor-alpha (TNF alpha) inhibits progesterone and estradiol-17beta production from cultured granulosa cells: presence of TNFalpha receptors in bovine granulosa and theca cells. Journal of Reproduction and Development $\mathbf{4 9}$ 441-449. (https://doi.org/10.1262/jrd.49.441)

Salamone DF, Damiani P, Fissore RA, Robl JM \& Duby RT 2001 Biochemical and developmental evidence that ooplasmic maturation of prepubertal bovine oocytes is compromised. Biology of Reproduction 64 1761-1768. (https://doi.org/10.1095/biolreprod64.6.1761)

Santulli P, Marcellin L, Tosti C, Chouzenoux S, Cerles O, Borghese B, Batteux F \& Chapron C 2015 MAP kinases and the inflammatory signaling cascade as targets for the treatment of endometriosis? Expert Opinion on Therapeutic Targets 19 1465-1483. (https://doi.org/10.1517 /14728222.2015.1090974)

Schwall RH, Mason AJ, Wilcox JN, Bassett SG \& Zeleznik AJ 1990 Localization of inhibin/activin subunit mRNAs within the primate ovary. Molecular Endocrinology 4 75-79. (https://doi.org/10.1210/mend-4-1-75)

Sirard MA, Picard L, Dery M, Coenen K \& Blondin P 1999 The time interval between FSH administration and ovarian aspiration influences the development of cattle oocytes. Theriogenology 51 699-708. (https:// doi.org/10.1016/S0093-691X(99)00019-9)

Sirard M-A, Richard F, Blondin P \& Robert C 2006 Contribution of the oocyte to embryo quality. Theriogenology 65 126-136. (https://doi. org/10.1016/j.theriogenology.2005.09.020)

Sriraman V, Sinha M \& Richards JS 2010 Progesterone receptorinduced gene expression in primary mouse granulosa cell cultures. Biology of Reproduction 82 402-412. (https://doi.org/10.1095/ biolreprod.109.077610) 
Traut MH, Berg D, Berg U, Mayerhofer A \& Kunz L 2009 Identification and characterization of $\mathrm{Ca} 2+$-activated $\mathrm{K}+$ channels in granulosa cells of the human ovary. Reproductive Biology and Endocrinology 728.

Tseng GC, Ghosh D \& Feingold E 2012 Comprehensive literature review and statistical considerations for microarray meta-analysis. Nucleic Acids Research 40 3785-3799. (https://doi.org/10.1093/nar/gkr1265)

Tsujimoto Y 1997 Apoptosis and necrosis: intracellular ATP level as a determinant for cell death modes. Cell Death and Differentiation 4 429-434. (https://doi.org/10.1038/sj.cdd.4400262)

Vassena R, Mapletoft RJ, Allodi S, Singh J \& Adams GP 2003 Morphology and developmental competence of bovine oocytes relative to follicular status. Theriogenology 60 923-932. (https://doi.org/10.1016/S0093691X(03)00101-8)

Welt CK \& Schneyer AL 2001 Differential regulation of inhibin B and inhibin a by follicle-stimulating hormone and local growth factors in human granulosa cells from small antral follicles. Journal of Clinical Endocrinology and Metabolism 86 330-336.

Welt CK, Adams JM, Sluss PM \& Hall JE 1999 Inhibin A and inhibin B responses to gonadotropin withdrawal depends on stage of follicle development. Journal of Clinical Endocrinology and Metabolism 84 2163-2169.

Yamamoto Y, Kuwahara A, Taniguchi Y, Yamasaki M, Tanaka Y, Mukai Y, Yamashita M, Matsuzaki T, Yasui T \& Irahara M 2015 Tumor necrosis factor alpha inhibits ovulation and induces granulosa cell death in rat ovaries. Reproductive Medicine and Biology 14 107-115. (https://doi. org/10.1007/s12522-014-0201-5)

Yang Q, Yan D \& Wang Y 2006 K + regulates DNA binding of transcription factors to control gene expression related to neuronal apoptosis. Neuroreport 17 1199-1204. (https://doi.org/10.1097/01.wnr.0000224)

Yang Y, Jiang G, Zhang P \& Fan J 2015 Programmed cell death and its role in inflammation. Military Medical Research 2 12. (https://doi. org/10.1186/s40779-015-0039-0)
Yoo J-Y, Shin H, Kim TH, Choi W-S, Ferguson SD, Fazleabas AT, Young SL, Lessey BA, Ha U-H \& Jeong J-W 2014 CRISPLD2 is a target of progesterone receptor and its expression is decreased in women with endometriosis. PLOS ONE 9 e100481. (https://doi.org/10.1371/journal. pone.0100481)

Yu SP 2003 Regulation and critical role of potassium homeostasis in apoptosis. Progress in Neurobiology 70 363-386. (https://doi. org/10.1016/S0301-0082(03)00090-X)

Zervou S, Whittington HJ, Ostrowski PJ, Cao F, Tyler J, Lake HA, Neubauer S \& Lygate CA 2017 Increasing creatine kinase activity protects against hypoxia/reoxygenation injury but not against anthracycline toxicity in vitro. PLOS ONE 12 e0182994. (https://doi.org/10.1371/journal. pone.0182994)

Zhang H, Kho AT, Wu Q, Halayko AJ, Limbert Rempel K, Chase RP, Sweezey NB, Weiss ST \& Kaplan F 2016 CRISPLD2 (LGL1) inhibits proinflammatory mediators in human fetal, adult, and COPD lung fibroblasts and epithelial cells. Physiological Reports 4 e12942. (https:// doi.org/10.14814/phy2.12942)

Zhou M, Wang Y, Qi S, Wang J \& Zhang S 2011 The expression of a mitochondria-localized glutamic acid-rich protein (MGARP/OSAP) is under the regulation of the HPG axis. Endocrinology 152 2311-2320. (https://doi.org/10.1210/en.2011-0050)

Received 10 April 2018

First decision 8 May 2018

Revised manuscript received 25 May 2018

Accepted 15 June 2018 